\title{
ELABORATION OF THE RESEARCH METHOD FOR MILK DISPERSION IN THE JET-SLOT TYPE HOMOGENIZER
}

\author{
Kyrylo Samoichuk \\ Department of Processing and Food Production Equipment named after professor F. Yalpachik \\ samoichuk.k@ukr.net \\ Alexandr Kovalyov \\ Department of Processing and Food Production Equipment named after professor F. Yalpachik ${ }^{1}$ \\ koba_o@ukr.net \\ Vadym Oleksiienko \\ Department of Processing and Food Production Equipment named after professor F. Yalpachik ${ }^{1}$ \\ vadym.oleksiienko@tsatu.edu.ua \\ Nadiia Palianychka \\ Department of Processing and Food Production Equipment named after professor F. Yalpachik ${ }^{1}$ \\ palyanichkan@gmail.com \\ Dmytro Dmytrevskyi \\ Department of the processes and equipment of food, hotel and restaurant industry named after \\ M. I. Belyaev2 \\ dmitrevskyidv@gmail.com \\ Vitalii Chervonyi \\ Department of the processes and equipment of food, \\ hotel and restaurant industry named after M. I. Belyaev ${ }^{2}$ \\ chervonyi.v@gmail.com

\section{Dmytro Horielkov} \\ Department of the processes and equipment of food, \\ hotel and restaurant industry named after M. I. Belyaev ${ }^{2}$ \\ gorelkov.dmv@gmail.com

\section{Inna Zolotukhina} \\ Department of the processes and equipment of food, \\ hotel and restaurant industry named after M. I. Belyaev ${ }^{2}$ \\ zolotce5@gmail.com

\section{Alina Slashcheva} \\ Chair of technologies in restaurant industry, hotel and restaurant business and entrepreneurship \\ Donetsk National University of Economics and Trade named after Mikhail Tugan-Baranovsky \\ 16 Tramvayna str., Kryvyi Rih, Ukraine, 50005 \\ slashcheva@donnuet.edu.ua \\ ${ }^{1}$ Dmytro Motornyi Tavria State Agrotechnological University \\ 18 B. Khmelnistskiy ave., Melitopol, Ukraine, 72312 \\ ${ }^{2}$ Kharkiv State University of Food Technology and Trade \\ 333 Klochkivska str., Kharkiv, Ukraine, 61051
}

\section{Abstract}

The competitiveness improvement of milk products is directly connected with a problem of decreasing energy consumption of the process of milk emulsion dispersion. At creating promising types of energy effective dispersers, a necessary condition is to elaborate a correct methodology for studying them that takes into account the specificity of the process of fat milk microemulsion dispersion.

Based on the critical analysis of research methods for homogenizers of different types, there have been determined main directions of their improvement, taken into account in the elaborated research method for a promising jet-slot type milk homogenizer. 
The method of theoretical studies, including a choice and analysis of stable and changeable factors of the homogenization process in a jet-slot type homogenizer and optimization criteria, has been elaborated. The interconnection of technological, constructive, hydraulic parameters with a dispersion quality has been demonstrated.

The influence of physical-mechanical properties of milk as a research object was taken into account. An optimal milk temperature was chosen for the studies. Factor variation limits have been substantiated. The constructive scheme of a chamber for the experimental homogenizer has been developed.

At processing the experimental research methodology, the main stage was to develop an experimental set for studying the influence of changeable factors of the dispersion process on a homogenization quality.

Dispersion quality estimation methods have been analyzed and the method of microphotography has been chosen with further computed analysis of obtained data.

The elaborated methodology was used at studying the influence of cream fat and ring slot width on a dispersion quality in a jet-slot type homogenizer. The obtained data allow to determine rational parameters of cream fat $-40-50 \%$ and slot width $-0.1 \mathrm{~mm}$. The analysis of dispersed characteristics of the milk emulsion allows to make a conclusion about the high homogenization quality, comparing with processing in a valve homogenizer.

Keywords: dispersion; milk homogenization; jet-slot type homogenizer; dispersion quality.

DOI: $10.21303 / 2504-5695.2020 .001436$

\section{Introduction}

It is possible to improve the competitiveness of milk products at providing the high assimilability of nutritive substances of a multicomponent product. One of methods for increasing the assimilability of milk and milk products is to increase fat phase milk emulsion dispersion [1, 2]. Homogenization is realized for decreasing an average diameter of fat globules of milk products and their even distribution in milk plasma. Dispersion advantages may be considered as a nutritive quality, storage term increase, commodity and taste qualities improvement in milk products $[1,3]$. Among shortcomings of the process, we may separate high specific energy consumption of homogenization (microfluidizers, valve) and a high average diameter of fat globules, comparing with most spread and best by this parameter - valve homogenizers (vibrating, electrohydraulic, centrifugal) $[2,4]$.

A possible method for solving the problem of homogenizers is creation of a high velocity difference of dispersing and dispersed phases at developing a construction, which operation principle provides separate feeding of skimmed milk and cream $[5,6]$. The most promising in the aspect of energy effectiveness is a construction of a jet-slot type milk homogenizer with separate cream feeding $[7,8]$. But at creating new promising homogenizers, it is necessary to create a method for studying the process of fat phase dispersion. Special attention must be paid to the study of an influence of constructive parameters on an average diameter of milk fat globules.

Despite the essential amount of developed homogenizers, existing methods of their study have essential shortcomings [3, 9, 10]:

- a unitary theory of homogenization that may be used as a background for elaborating the methodology for studying homogenization is absent;

- impossibility of visual observation on the process of fat globules disruption;

- absence of a computer model of milk fat globules disruption;

- absence of state standards for determining milk dispersion and homogenization quality.

So, the aim of the work is to elaborate the method for studying the promising jet-slot type milk homogenizer. For attaining the set aim, it is necessary to perform the following tasks, taking into account the aforesaid shortcomings:

- to take into account the interconnection between constructive and technological factors, influencing a homogenization quality;

- to choose a method for determining a dispersion quality.

\section{Materials and Methods}

At elaborating the method of analytic studies, there were used: classic dependencies of mechanics and hydraulics, criterial hydrodynamic equations, process modeling in the program com- 
plex of finite element analysis ANSYS. The last ones include computer programs for constructing a geometric model of a homogenizer chamber (SolidWork) and analysis of hydrodynamic parameters of a flow (ANSYS, COSMOSFloWorks).

At elaborating the experimental research methodology, there was used the microphotography method by a digital camera and optic microscope and processing of the obtained results by the computer program of images analysis.

A research object is cow drinking milk, fat 2-4\% (Milk and liquid milk products) ISO 9622:2013 [11]. Samples were taken according to (Milk and milk products. Guidance on sampling) ISO 707:2013 [12].

\section{Elaboration of the research methodology}

\section{1. Elaboration of the theoretical research methodology}

As a result of the conducted analysis of literary sources about research methods and methodologies for milk fat phase dispersion, the general program of studying the jet-slot type milk homogenizer has been elaborated (Fig. 1). The program provides conduction of analytic and experimental studies, finding of rational parameters of the process and probation of obtained results under production conditions.

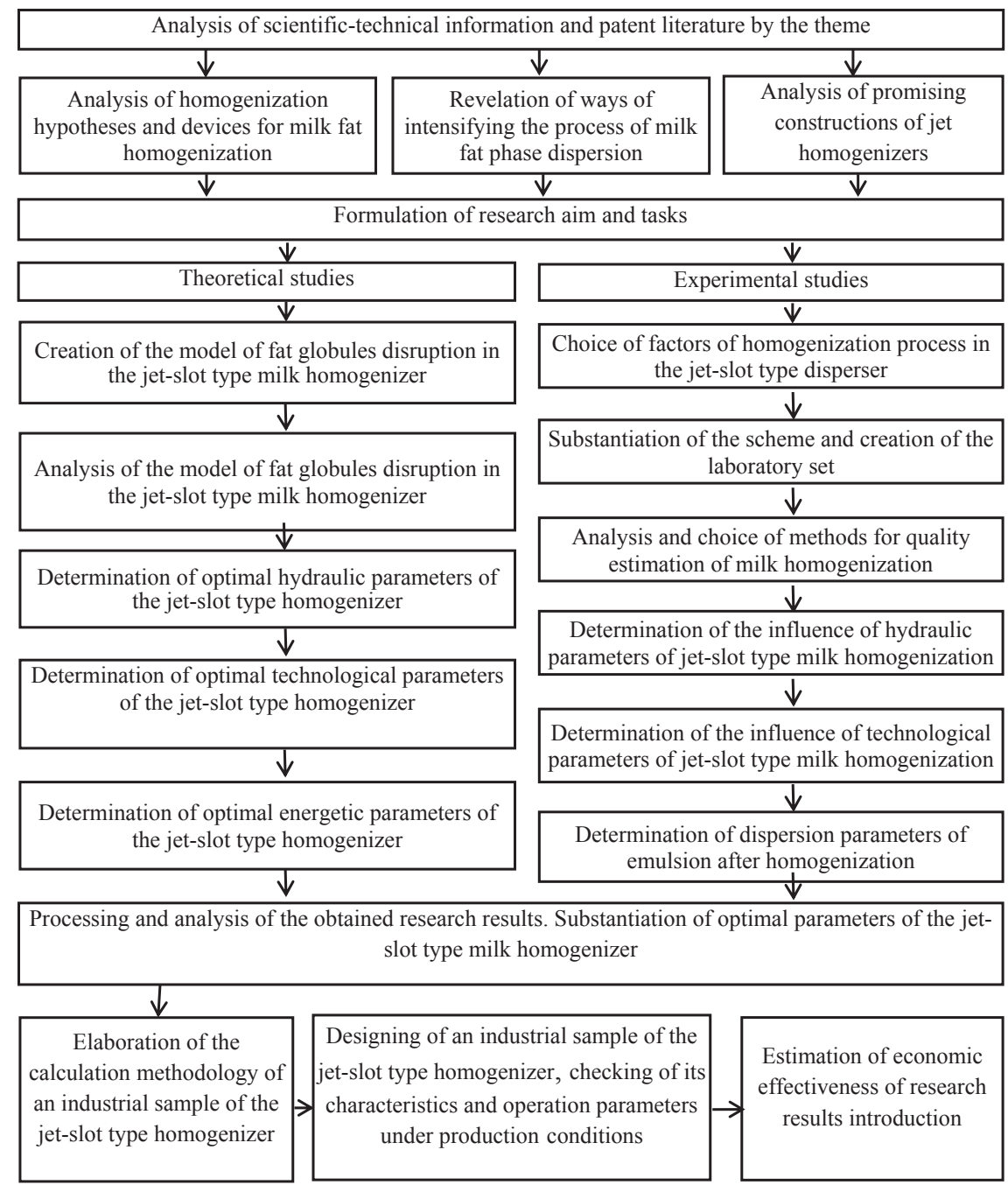

Fig. 1. Structural scheme of research

The main task of the theoretical studies is: to substantiate parameters and operation modes of the jet-slot type milk homogenizer with separate cream feeding (JSHSC) for get- 
ting the milk emulsion dispersion at level $0.80-0.85 \mu \mathrm{m}$ at minimal energy consumption of the process.

At analyzing literary sources, the following factors of the milk homogenization process in JSHSC were determined (Fig. 2) [7, 13, 14]:

- constructive: chamber diameter in the most narrow spot of a confuser $d_{c}$, ring slot length $l_{s}$ and ring slot width $h$.

- technological: skimmed milk feeding velocity $v_{s k}$, cream feeding velocity $v_{c}$, fat phase feeding $Q_{f}$, homogenization productivity $Q_{h}$, average diameter of a fat globule after homogenization $d_{a v}$, homogenization temperature $T$.

- hydraulic: skimmed milk feeding pressure $\Delta \mathrm{p}_{s k}$.

Physical-chemical parameters of milk: milk density $\rho_{m}$, milk plasma density $\rho_{p l}$, milk fat density $\rho_{f}$, surface tension on the boundary of fat-plasma phases $\sigma_{f-p}$, acidity ${ }^{\circ} \mathrm{T}$, kinematic and dynamic viscosity of milk, plasma and water fat $\mu, v, \mu_{p l}, v_{p l}, \mu_{f}, v_{f}$ respectively.

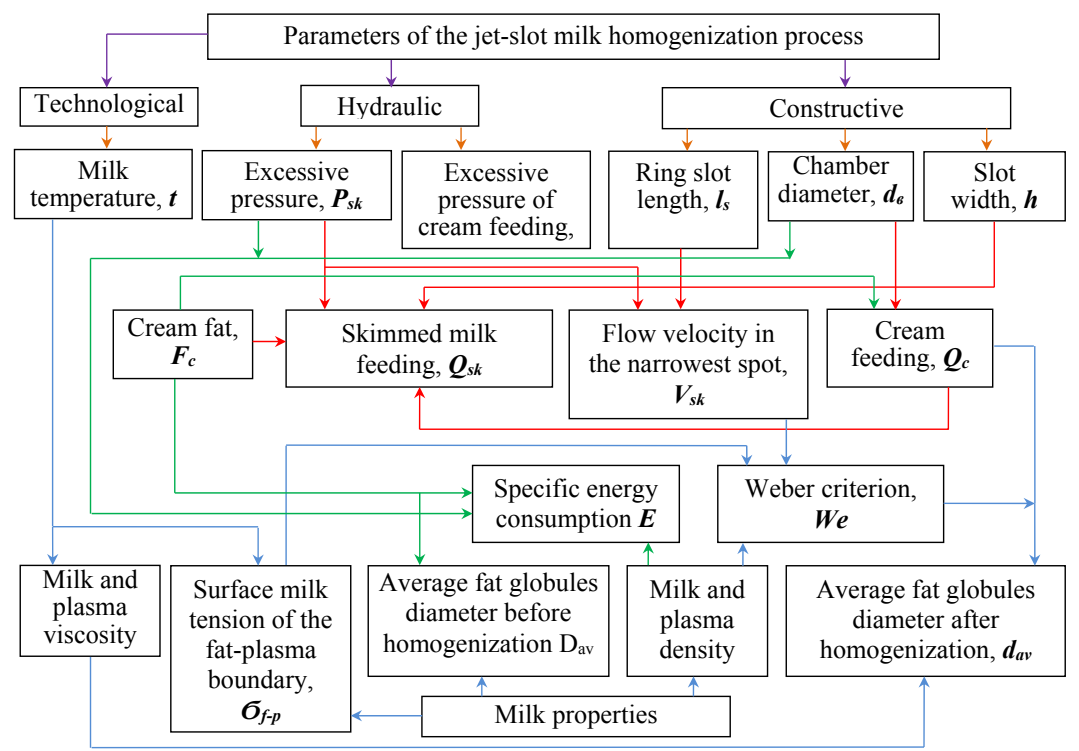

Fig. 2. Interconnection between main factors, initial parameters and optimization criteria in JSHSC

Optimization criteria: average diameter of a fat globule after homogenization $d_{a v}$, power, consumed by JSHSC P, specific energy consumption of JSHSC, $E_{s p}$.

For modern milk technological processes, it is completely enough to maintain production with the average diameter of fat globules after homogenization as $0.8-0.85 \mu \mathrm{m}$. But further dispersion increase means disruption at the level, close to one of chylomicrons, so better assimilation of milk products $[1,4]$.

The velocity of skimmed milk feeding, according to the jet-slot milk homogenizer with separate cream feeding, closest by the operation principle and construction, must vary from 30 to $90 \mathrm{~m} / \mathrm{s}$. The distance in the homogenizer slot varies within value diapason $0.1-0.9 \mathrm{~mm}$ [15]. The fat of cream, used at the studies varied in diapason $10-50 \%[1,7]$.

The temperature of milk homogenization by technological requirements is $40-70{ }^{\circ} \mathrm{C}$. The low limit is conditioned by the temperature of complete melting of milk fat, transformed to the liquid condition, and the high one - by changes in physical properties of milk, taking place at pasteurization and not desirable for homogenization [1].

As a result of the analysis of existing constructions, there was offered the constructive scheme of the jet-slot type milk homogenizer (Fig. 3). The chamber of JSHSC (Fig. 3) consists of confuser 2 , and diffuser 5 , branch pipes for feeding and removal of a ready product 1 and 6 , container with cream 4 and ring slot 3 [8]. Preliminarily skimmed milk with fat $F_{s k}$ is supplied with 
velocity $v_{s k}$ through branch pipe 1 . In the most narrow spot of confuser 2 with diameter $d_{c}$ cream with fat $F_{c}$ is supplied from container 4 through narrow ring slot 3 of width h with velocity $v_{c}$.

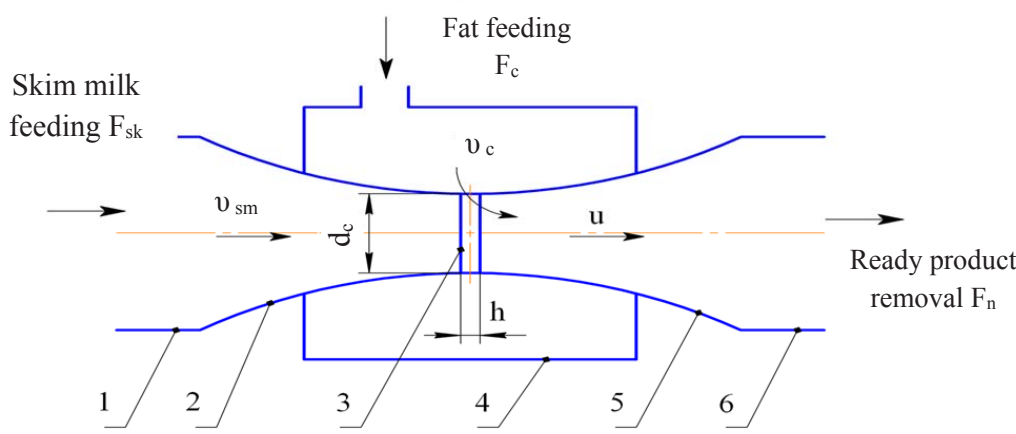

Fig. 3. Constructive-technological scheme of the chamber of the jet-slot type milk homogenizer: 1 - branch pipe for skim milk feeding; 2 - confuser; 3 - ring slot; 4 - container with cream;

5 - diffuser; 6 - branch pipe for ready product removal; $v_{c}$ - velocity of cream feeding; $v_{s k}$ - velocity of skimmed milk feeding; $d_{c}$ - confuser diameter in the most narrow spot; $h$ - width of the ring slot; $u$-sliding velocity of fat globules as to the milk plasma; $F_{s k}$ - fat of skimmed milk; $F_{c}$ - cream fat; $F_{n}$ - ready product fat

At entering the ring jet of cream in the skimmed milk flow, the high velocity of fat globules streamline forms and results in the Weber criterion growth. As a result, at transferring to the wide spot of diffuser 5 fat globules are disrupted. Homogenized and normalized milk with fat $F_{n}$ is removed through branch pipe 6 .

\section{2. Elaboration of experimental research method}

For realizing the program of experimental studies (Fig. 2) it is necessary:

- to develop the experimental set for studying the process of JSHSC, allowing to regulate main factors of the process;

- to choose the method for homogenization quality estimation;

- to conduct experimental studies for finding the influence of the process factors on optimization criteria.

The developed laboratory set for studying the dispersion process in JSHSC is presented in work [15]. The main center of the developed set is the homogenization chamber of JSHSC. Its construction, given on Fig. 4, $\boldsymbol{a}, \boldsymbol{b}$, provides formation of the maximal velocity difference between a fat globule and skimmed milk that is a base of effective disruption of fat globules.

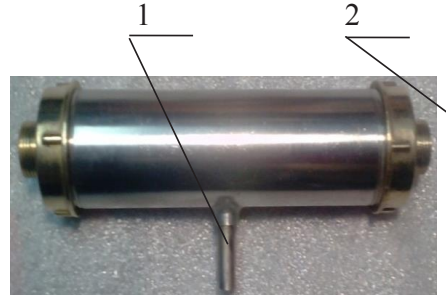

$a$

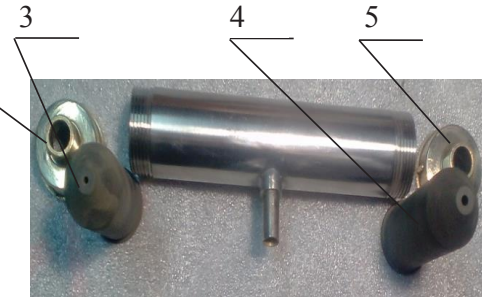

$b$

Fig. 4. Assembled chamber (a) and JSHSC chamber construction (b):

1 - branch pipe of cream feeding; 2 - branch pipe for skimmed milk feeding; 3 - confuser; 4 - diffuser; 5 - branch pipe for homogenized milk removal [16]

The chamber of the jet type milk homogenizer (Fig. 4, b) consists of confuser 3 and diffuser 4 , forming the narrowest place in the central part of the chamber. Preliminarily skimmed milk is supplied through feeding branch pipe 2, after which reaches the narrowest spot, where the 
necessary amount of cream is added through the slot between the confuser and diffuser through supplying branch pipe 1 to skimmed milk that has the most velocity in this place [8]. Homogenized milk is removed through branch pipe 5 .

The number of iterations of each experiment is 3. Such number provides an error no more $5 \%$, that is acceptable for studying the dispersion process.

Main quality parameters of multicomponent dispersed products include: dispersed phase distribution by fractions of different sizes, homogeneity, stableness, structural-mechanical properties of a product, determined as physical-chemical properties of components and processing technologies $[1,13]$. So, there is a need in a distinct, fast method of emulsion quality estimation. Ways of homogenization quality estimation may be divided in groups [10, 17]:

1. Mechanical separation that is operation of two phases stratification.

2. Sedimentation analysis, based on separation of groups of samples by weight.

3. Centrifuging method that is in fractioning emulsion components by the influence of efferent efforts.

4. Analytic method of fat phase stableness estimation, based on consideration of the process of fat phase sedimentation.

5. Optic method.

6. Microscope method.

Methods 1-5 allow to estimate the emulsion quality fast, but they have common shortcomings, connected with indirect measuring of dispersed characteristics of the fat emulsion. So, it is inexpedient to use these methods at the stage of development and study of new types of homogenizers $[15,17]$. Method 6 is characterized by the high labor consumption, but allows to determine all necessary dispersed characteristics of the milk emulsion and to construct histograms of fat globules distribution by average sizes [18]. Thus, the choice of the microphotography method with further analysis of obtained milk samples is substantiated as most rational one under condition of quality parameters of the jet-slot milk homogenization process. For obtaining microphotos, we use an optic microscope Micromed P-1-LED (Russia) with general magnification 1500 . The microscope is equipped by a digital camera Mustek Wcam 300 (Taiwan) with discrete capacity $640 \times 480$, connected to a personal computer or a digital camera with high resolution.

The quality of the milk homogenization process is determined by parameters of the average diameter of fat globules (AFG) and the distribution width of the milk emulsion dispersed composition. The last parameter may be visually assessed by a histogram of fat globules distribution by sizes, and quantitatively - by variation coefficient.

\section{Approbation of results and Discussion}

The elaborated methodology is used at studying the influence of cream fat and ring slot width on the dispersion quality in the jet-slop homogenizer. The results of the experimental studies of the type of dependence between cream fat $F_{c}$ and slot width of the homogenization chamber in the narrowest spot $h$ are presented in Table 2.

Table 2

The data of the experimental studies of the type of dependence between cream fat $F_{c}$ and ring slot width of JSHSC $h$

\begin{tabular}{cccccc}
\hline \multirow{2}{*}{ Slot width, h, mm } & \multicolumn{5}{c}{ Cream fat $\boldsymbol{F}_{c}, \boldsymbol{\%}$} \\
\cline { 2 - 6 } & $\mathbf{1 0}$ & $\mathbf{2 0}$ & $\mathbf{3 0}$ & $\mathbf{4 0}$ & $\mathbf{5 0}$ \\
\hline 0.1 & 0.75 & 0.80 & 0.77 & $\mathbf{0 . 7 4}$ & $\mathbf{0 . 7 3}$ \\
0.5 & 0.79 & 0.85 & 0.80 & 0.79 & 0.77 \\
0.9 & 0.84 & 0.83 & 0.85 & 0.84 & 0.80
\end{tabular}

The obtained data analysis (Table 2) testifies that at fat increasing of the cream, supplied to JSHSC, a dispersion degree grows. 
Least AFG values may be reached at using cream, which fat is $40-50 \%$ and minimal slot width $0.1 \mathrm{~mm}$. At decreasing the cream fat less 10-20\%, the unessential AFG decrease also takes place. But at using synchronous milk normalization by fat, it is not rational to use cream of such fat in practice. AFR depends on the ring slot width and at its increase from $h=0.1$ to $h=0.9 \mathrm{~mm}$ at using cream with fat $30 \%$ the dispersion parameters worsen by $10 \%$.

The dispersion analysis of the obtained data for $F_{c}=40 \%, v_{c}=20 \mathrm{~m} / \mathrm{s}, h=0.5 \mathrm{~mm},(\mathbf{F i g}$. 5, 6) demonstrated that after processing in JSHSC, the variation coefficient is lower than the analogous parameter for valve homogenizers by $17 \%$. At that AFG of the product, processed in JSHSC, is by $7 \%$ less than in valve ones, considered as best by this parameter [19, 20].

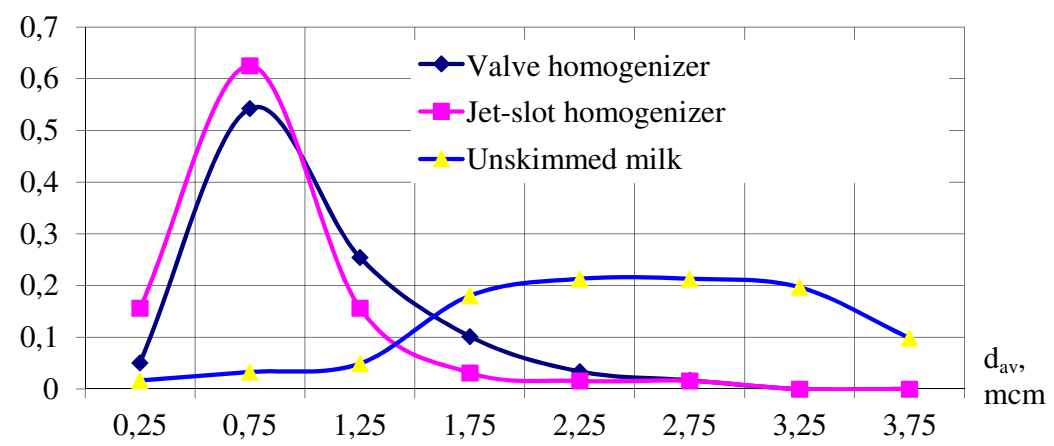

Fig. 5. Histogram of the fat globules average diameter distribution by size groups

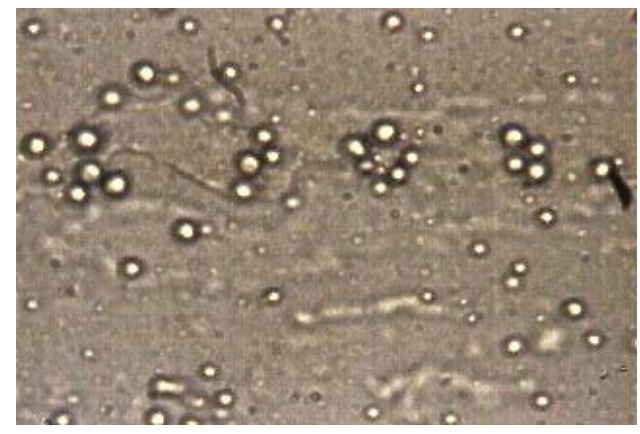

$a$

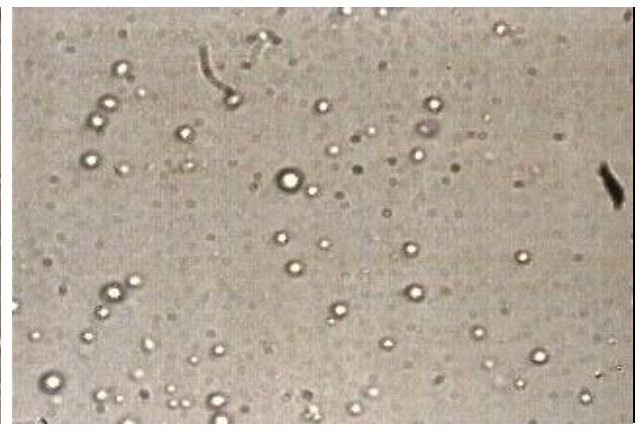

$b$

Fig. 6. Microphotos of homogenized milk at using cream: $a$ - fat $60 \% ; b$ - fat $40 \%$

The analysis of the given microphotos (Fig. 6) testifies that the use of cream with fat higher $50 \%$ without its previous homogenization results in homogenized milk with AFG at level 0.75$0.83 \mathrm{mcm}$. But the absence of enough capsule liquid results in conglomerations formation that excludes the use of cream with fat higher $50 \%$ [20].

\section{Conclusions}

The methodology of the analytic studies of the jet-slot type milk homogenizer that includes the choice of homogenization process factors and optimization criteria in their interconnection has been elaborated. The constructive scheme of the experimental homogenizer has been developed.

The methodology of the experimental studies, based on the laboratory set for conducting them, has been elaborated. The microphotography method with further computer analysis of the obtained data has been chosen for homogenization quality estimation.

The elaborated methodology was probated at studying the cream fat and ring slot width influence on the dispersion quality in the jet-slot type homogenizer. The obtained data allow to determine the rational parameters of cream fat as $40-50 \%$ and slot width $-0.1 \mathrm{~mm}$. The analysis of dispersed characteristics of milk emulsion testifies to the variation coefficient decrease, comparing with valve homogenizers by $17 \%$, and average fat globules diameter - by $7 \%$. 


\section{References}

[1] Gorbatova, K. K., Gun'kova, P. I. (2010). Biohimiya moloka i molochnyh produktov. Sankt-Peterburg: GIORD, 336.

[2] Fialkova, E. A. (2006). Gomogenizatsiya. Noviy vzglyad. Sankt-Peterburg: GIORD, 392.

[3] Tartar, L. (2009). The General Theory of Homogenization. Lecture Notes, 470.

[4] Huppertz, T. (2011). Homogenization of Milk | Other Types of Homogenizer (High-Speed Mixing, Ultrasonics, Microfluidizers, Membrane Emulsification). Encyclopedia of Dairy Sciences, 761-764. doi: https://doi.org/10.1016/b978-0-12-3744074.00226-0

[5] Fonte, C. P., Fletcher, D. F., Guichardon, P., Aubin, J. (2020). Simulation of micromixing in a T-mixer under laminar flow conditions. Chemical Engineering Science, 222, 115706. doi: https://doi.org/10.1016/j.ces.2020.115706

[6] Roudgar, M., Brunazzi, E., Galletti, C., Mauri, R. (2012). Numerical Study of Split T-Micromixers. Chemical Engineering \& Technology, 35 (7), 1291-1299. doi: https://doi.org/10.1002/ceat.201100611

[7] Samoichuk, K., Kovalyov, A., Palyanichka, N., Kolodiy, A., Lebed, M. (2019). An experimental study of parameters in the slot type jet-mixing homogenizer of milk. Proceedings of the Tavria State Agrotechnological University, 19 (2), $117-129$. doi: https://doi.org/10.31388/2078-0877-19-2-117-129

[8] Samoichuk, K., Zhuravel, D., Viunyk, O., Milko, D., Bondar, A., Sukhenko, Y. et. al. (2020). Research on milk homogenization in the stream homogenizer with separate cream feeding. Potravinarstvo Slovak Journal of Food Sciences, 14, $142-148$. doi: https://doi.org/10.5219/1289

[9] Ward, K., Fan, Z. H. (2015). Mixing in microfluidic devices and enhancement methods. Journal of Micromechanics and Microengineering, 25 (9), 094001. doi: https://doi.org/10.1088/0960-1317/25/9/094001

[10] Morales, J. O., Watts, A. B., McConville, J. T. (2016). Mechanical Particle-Size Reduction Techniques. AAPS Advances in the Pharmaceutical Sciences Series, 165-213. doi: https://doi.org/10.1007/978-3-319-42609-9_4

[11] ISO 9622:2013. Milk and liquid milk products.

[12] ISO 707:2013. Milk and milk products. Guidance on sampling.

[13] Walstra, P., Geurts, T. J., Noomen, A., Jellema, A., Van Boekel, M. A. J. S. (1999). Dairy technology: Principles of Milk Properties and Processes. Part II: Processes. New York: Marcel Dekker Inc, 246.

[14] Postelmans, A., Aernouts, B., Jordens, J., Van Gerven, T., Saeys, W. (2020). Milk homogenization monitoring: Fat globule size estimation from scattering spectra of milk. Innovative Food Science \& Emerging Technologies, 60, 102311. doi: https:// doi.org/10.1016/j.ifset.2020.102311

[15] Samoichuk, K., Kovalev, A. (2011). The designing laboratory pattern of jet - mixing homogenizer with separated giving of creams. Pratsi TDATU, 6 (11), 77-84.

[16] Strumynno-shchilynnyi homohenizator moloka. Available at: http://www.tsatu.edu.ua/ophv/naukova-dijalnist/rozrobky-kafedry/strumynno-shhilynnyj-homoheni3ator-moloka/

[17] Samoichuk, K., Kovalov, A., Ivzhenko, A. (2012). Analysis of methods of estimation of quality of homogenization of milk. Pratsi Tavriyskoho derzhavnoho ahrotekhnolohichnoho universytetu, 4 (12), 222-229.

[18] Chapter 6.3. Homogenisers. Dairy Processing Handbook (2003). (2003). Lund, 115-122.

[19] Hussong, J., Lindken, R., Pourquie, M., Westerweel, J. (2009). Numerical Study on the Flow Physics of a T-Shaped Micro Mixer. IUTAM Bookseries, 191-205. doi: https://doi.org/10.1007/978-90-481-2626-2_15

[20] Ciron, C. I. E., Gee, V. L., Kelly, A. L., Auty, M. A. E. (2010). Comparison of the effects of high-pressure microfluidization and conventional homogenization of milk on particle size, water retention and texture of non-fat and low-fat yoghurts. International Dairy Journal, 20 (5), 314-320. doi: https://doi.org/10.1016/j.idairyj.2009.11.018 